\title{
The element of digital transformation of regional network - an aggregator
}

\author{
Felix Byk $^{1, *}$ and Lyudmila Myshkina ${ }^{1}$ \\ ${ }^{1}$ Novosibirsk state technical university, Karla Marksa, 20, Novosibirsk, Russia
}

\begin{abstract}
PJSC "Rosseti" is forced to find new ways of getting additional income. It's caused by the insufficient financing of network. But a lot of known and supported by network organizations initiatives are leading to the increase of network component in electricity cost for consumers. By the way the new subject, called demand side response aggregator in the UPS, is appeared in power engineering. This problem can be partially solved by the large regional network companies in case of them being an aggregator. At the same time, the efficiency of the aggregator function increases in case of using local power systems as a subject of the retail market as a regulatory resource. It'll let to avoid the decrease of the power consumption and transmitted power volume, to increase the reliability and the quality of power supply due to reduce of power losses in network. It's obvious, that the appropriate automation is needed as an element of the digital transformation of the electric network.
\end{abstract}

\section{Introduction}

The implementation of functions related to the power supply to the terminal consumers was the main source of income for network organizations up to this day:

- Transmission and distribution of electricity;

- Technical connection of new consumers,

The known insufficient financing of network organizations is caused by the presence of state regulation and the lack of investment attractiveness. This aspect forces them to search for additional sources of income and new technical solutions to fulfill their own functions related to ensuring of reliable and high-quality power supply. It explains the following initiatives of PJSC "Rosseti":

- Initiation of the fee for reserved electricity;

- Inclusion of an investment component in the tariff for the consolidation of existing independent territorial network organizations;

- Initiation of differential transmission tariffs in the UPS.

These initiatives are supported by the Ministry of Power Engineering.

However, according to the Ministry of Economics, the introduction of fees for reserved electricity will lead to a slowdown of the economy and multibillion consumer losses. Federal Antimonopoly Service considers that the differentiation of the Federal Network Company tariff will make the industry leave the UPS. It will also lead to the decrease of consumption and the increase of cross subsidization and tariffs [1]. The increase of consumers' payments will not be more than 138 billion rubles. It will reduce the physical volume of industrial production on 0.5 percent and the production cost will increase on 5-9\%. The total economic losses in 2020-2024 may reach the amount of 686 billion rubles (in prices of 2019) amid a decline in industrial investment by $0.18 \%$ till 2024 .

Obviously, the containment of these network initiatives is an attempt to protect industry, communal services and public sector employees, and to force the network monopoly to increase its own efficiency, primarily due to the digital transformation of the industry. Otherwise, the UPS turns into a source of uninterrupted growth of the tariff load for the industry from a source of uninterrupted supply of electricity and stimulates the leaving to their own generation. Also it's obvious that the PJSC Rosseti got obligations to carry out the digital transformation of the network due to the "Digital Transformation" concept adoption in 2018. These obligations for sure require additional funds.

But the new subject, called demand side response aggregator in the UPS, is appeared in power engineering in 2019. Any subject of power engineering, including regional electric network companies, can perform its functions according to the [2]. The performance of aggregator functions by regional electric network companies may be accompanied by the extraction of significant technical and economic effects. The amount of these effects may be enough for the digital transformation.

\section{Demand side response aggregator creation}

Demand side response aggregators creation in Russia is considered as a solution of the insufficiency of managed

Corresponding author: felixbyk@hotmail.com 
resource problem to cover peak loads. This creation is carried out in accordance with the Decree of the Government of the Russian Federation adopted in March 2019 [2]. The project was initiated by the System Operator as part of the implementation of the EnergyNet roadmap and consists of two stages. Launch of pilot projects for the providing the system reliability by aggregator is supposed to be carried out during 20192020. At the same time, the volume of change in participants' demand in pilot projects is limited to $0.1 \%$ of the capacity demand $[3,4]$. The direct participation of aggregators in the wholesale market is expected at the second stage. To embody it, during the pilot projects technical and technological solutions will be tested, demand side response aggregator for retail consumers will be formatted and active electricity consumers, able to adapt their consumption to the conditions in the energy system, will be created. It will ensure the participation of aggregators in the wholesale market of electricity and power from 2021 [5].

Substantially, demand side response aggregators are organizations that identify and coordinate the ability of a group of end users to manage their load and convert it into goods and services in the markets of electricity, power and system services. The main goals of managing demand for electricity are to reduce the peak load in the power system. It may be accompanied by decrease of prices on the electricity market and the prevention of excessive capital-intensive construction of power plants and networks. Demand management has become a fullfledged tool to ensure the balance of supply and demand in power systems of many countries over the past decade. According to Navigant Research, the global market volume for demand management goods and services in 2016 was $39 \mathrm{GW}$, and 28 of them are placed on the North America. In those $28 \mathrm{GW} 21 \mathrm{GW}$ are provided through demand management programs for commercial and industrial consumers and 7 are provided due to programs for household consumers and small businesses. The usage of this resource in the US power system avoids investments of 270 billion dollars (in prices of 2016) in the development of power engineering $[6,7]$.

The demand management resource in Russia may reach $13 \mathrm{GW}$. 6-10 GW are placed in the first price zone and 2-3 GW in the second one. The common economic effect of demand management in Russia is expected to be about 67-105 billion rubbles a year in the future.

System-wide effect will be shown by stabilization of electricity prices, alignment of the loading mode of generating and network equipment, which is manifested by increased durability, reduced requirements for controllability. Those factors are important for the digital transformation of control systems [8].

\section{First results}

Demand side response aggregators perform the commercial function of combining distributed demand management resources according to the developed rules [2]. Aggregators are acting as intermediaries between consumers providing their ability to change consumption and the buyer of demand management products. Aggregators acquire load reduction services from many consumers with different characteristics. Distributed aggregated load is one of the key benefits of aggregation.

Requirements for the aggregator [1]:

- The amount of controlled by the aggregator power must be at least $1 \mathrm{MW}$;

- Aggregator determines independently the number of consecutive hours per day in the amount of 2 or 4 hours. In these hours aggregator must be ready to provide the corresponding demand management services;

- The coefficient of accounting of the services volume will be 0.5 at work of 2 hours a day and 1 for 4 hours depending on the chosen number of hours.

Aggregators ensure their participation in several market segments by getting the necessary generalized resource for demand management. Those markets are electricity market, the day-ahead market, balancing market, the system services market of ensuring system reliability. The above is accompanied by the extraction of economic effects for the aggregator.

The composition of the aggregators is determined in the process of competitive selection. The criterion is to minimize the total cost of the total volume of the services provision for demand management of electricity [9]. According to the [2], the limited price of the provision of demand management services should not exceed the value of the price of power for the corresponding price zone.

The payment mechanism by the aggregator of the service for the resource provision is not fully formed and is developing as part of the pilot project.

Pilot aggregators' selection is held quarterly from the third quarter of 2019 (from July till September). The first selection showed interest in the new mechanism. The number of applications in the 1 st price zone exceeded the common volume fixed by the Government of the Russian Federation for 2019. 56.18 MW for the first price zone and 8.5 MW for the second were submitted for selection, Table 1.

Table 1. Common data for the first competitive selection of demand side response aggregators.

\begin{tabular}{|l|c|c|}
\hline \multicolumn{1}{|c|}{ Indicator } & $\begin{array}{c}\text { First } \\
\text { price } \\
\text { zone }\end{array}$ & $\begin{array}{c}\text { Second } \\
\text { price zone }\end{array}$ \\
\hline Limit of managed demand, MW & 39 & 11 \\
\hline Volume of applications, MW & 56 & 8.5 \\
\hline Limit price, rubles/MW per month & 795659 & 622841 \\
\hline $\begin{array}{l}\text { Actual limit price of selected } \\
\text { applications, rubles/MW per } \\
\text { month }\end{array}$ & 600000 & 620000 \\
\hline $\begin{array}{l}\text { Average price of selected } \\
\text { applications, rubles/MW per } \\
\text { month }\end{array}$ & 481355 & 580773 \\
\hline
\end{tabular}


Demand management services contracts were concluded with 22 participants. There are representatives of various power energy subjects among the participants in the selection, including two network organizations PJSC "Interregional Distribution Network Company of the South", PJSC "Interregional Distribution Network Company of the North Caucasus". 90\% of the selected applications use the load of small and medium-sized enterprises as a regulatory resource [10].

The results of the load aggregators' work are quantitatively expressed as a decrease in the price of electricity on the day-ahead market: the first mechanism operation reduced the price by $4.7 \%$ [11]. At the same time, the value of actual obligations fulfillment amounted to only $72 \%$ on 15.07 .2019 of the total value of the planned price-dependent decrease in the volume of electricity purchase. Readiness for unloading was declared for this obligations. It indicates the demand management effectiveness from the perspective of consumers and the system as a whole.

\section{Key effects for network companies}

It is important to note that demand management represents the unloading of consumer equipment at certain hours and not its redistribution in time. Therefore, this is accompanied by a decrease in power consumption and transmitted power through networks. It conflicts with the network companies interests if they do not assume the aggregator role. It will at least avoid a decrease in income.

According to the current regulatory legal acts, the aggregator is allowed to attract consumers with a generating capacity less than $25 \mathrm{MW}$. It is customary to refer them to local energy systems created based on the distributed generation which received the status of retail market entities due to technological connection to the grids of Distribution Network Company.

Attracting local energy systems' regulatory resources allows to redistribute the load schedule in time saving the volume of power consumption in the region and the size of electricity transmitted through distribution networks. Network companies will essentially allow crowding out the capacities of inefficient power plants and unloading Federal Network Company's networks by laying the peak load of small and medium-sized businesses and household consumers on the free generating capacities of local power systems. It will reduce the cost of network development.

According to the experts, reducing the construction of new network capacities need by reducing peak consumption can reach 120-180 MVA per year. It'll reduce the need of investment by 2-3 billion rubbles per year [8]. Obviously, this is in line with national economic development goals.

If the energy sales organizations perform the aggregator functions, it's possible to unload already lightly loaded substations. It contradicts with the interests of Distribution Network Company. Obviously, regional network companies are better informed than power supply companies on what $110 / 10 \mathrm{kV}$ substations the peak load is running. The peak load causes an equipment overload. That's why Distribution Network Companies can determine the places where the availability of a resource is most appropriate for managing demand and reducing peak load better than other power engineering subjects.

Network companies have certain priorities for performing the function of demand side response aggregator as subject of the power engineering. In addition, they have an interest in obtaining additional "hidden" effects from attracting excess generating capacities of local power systems as an aggregated resource. Distribution Network Companies are able to indicate where the availability of the regulatory resource is effective, including a professional consumer in the retail market as the local power system. Therefore Distribution Network Companies can stimulate their appearance in the coverage area of "red" $110 / 10 \mathrm{kV}$ substations as a demand side response aggregator. It will significantly increase the technical and economic efficiency of the networks functioning.

The "hidden" effects of Distribution Network Companies will not only be equalization of equipment loading. This is associated with the costs of their maintenance and services. Involving the generation of local power systems as an aggregated control resource will allow Distribution Network Companies to increase the reliability and quality of the services provided for the transmission of electricity ensuring their connection to the regional network [12]. It also provides several economic benefits. Connecting the local power systems provides next effects:

- The possibility of mutual reservation;

- The ability of using generator excitation regulators to maintain the voltage level in the nodes of the distribution network;

- The ability of performing multi-agent voltage regulation;

- $\quad$ Reducing the losses in network.

The growth of network technical efficiency allows to implement reliability and quality management and to take effect by increasing the tariff up to $2 \%$ [13], what is leading to income growth for Distribution Network Companies. It is important to note that using redundant local power systems capable of operating in island mode on principles of self-balance as a resource for aggregator implies the presence of appropriate automation, which ensures parallel operation of local and unified power systems. Their integration is beneficial not only for Distribution Network Companies, but also for distributed generation as the main energy source of local power systems. First of all, it's caused due to the increase of cogeneration source's Installed Capacity Utilization Factor. It reduces the cost of heat supply to consumers.

It should be noted that only the integration of the island local power system allows it to acquire the status of a retail market entity operating in the professional consumer mode, as a producer-consumer of electricity. This process depends largely on the Distribution Network Companies defining the technical conditions for connecting the local power system to the external 
network, which may include requirements for appropriate automation.

The specified requirements should allow to use regulatory resources of the local power system to perform the function of the aggregator, to control voltage in the distribution network nodes in the mode of parallel operation and to reduce restrictions in the power supply of responsible consumers in case of network equipment failures and power supply failure from the $110 / 10 \mathrm{kV}$ substations $[14,15]$.

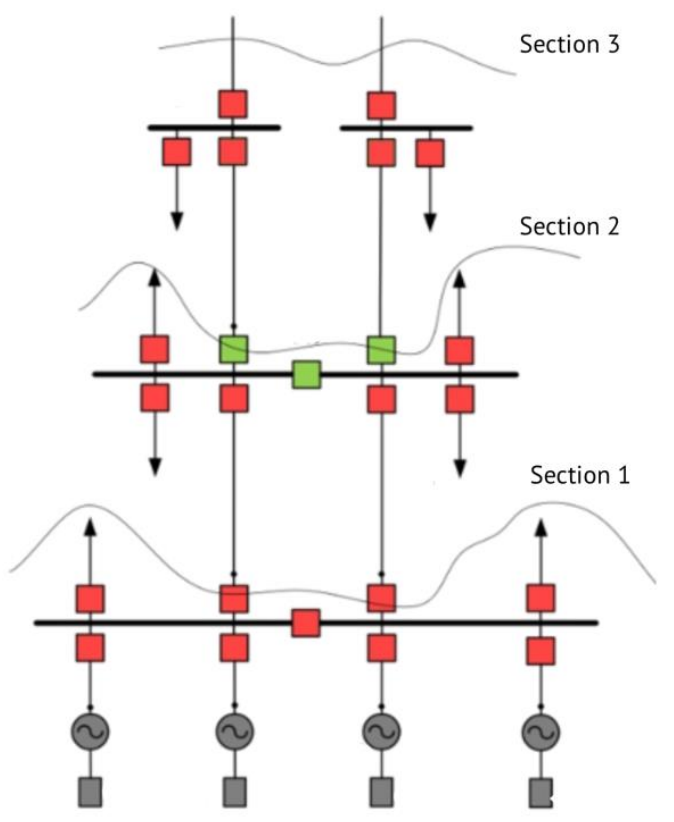

Fig. 1. Managed and controlled sections in integration

Three main sections for the automation system can be highlighted, each of them is used for management and accounting:

1. Operation mode and output electric power of the power source and its separation according to technological conditions from the local power system, afterwards power supply to consumers is carried out from the external network;

2. Supplied/consumed energy by the local power system, as a subject of the retail market operating in the professional consumer mode, and balanced separation of the local power system to the island mode according to the technological conditions of the external network operation;

3. Performing the requirements of the demand side response aggregator for the regulatory resources provision.

Nowadays, the manufacture and pilot operation of automatics ensuring the integration of the local power system to the external network is being completed [15]. Its development was carried out on the order of the network company JSC "Tyumenenergo" which is a $100 \%$ subsidiary of PJSC "Rosseti". Automation is introduced in JSC "Regional Electric Company" as a pilot object. JSC "Regional Electric Company" is
Distribution Network Company in Novosibirsk region. It is obvious that this new technological solution corresponds to the technical policy of PJSC "Rosseti" aimed at digitalization of the network [16]. The indicated transition to intelligent energy will increase their economic efficiency due to additional income from the market of system services, competitive power selection and wholesale electricity and capacity market. Network companies will perform the functions of the aggregator in this transition. According to experts estimates expected economic effects will reach up to 67-105 billion rubbles per year and the network component won't increase in the final cost of electricity for consumers.

\section{Conclusions}

It will be possible to extract significant technical and economic effects that may be sufficient for the digital transformation when the demand side response aggregators will advent and network organizations will start acting as them.

Attraction of power systems as an adjustment resource will allow:

- Regional network companies to receive additional incomes from the market of system services, competitive power selection and wholesale electricity and capacity market;

- To increase income from improving the reliability and quality of their electricity transmission services;

- To reduce capital investment in development and operational costs.

Recoverable economic effects from cost reduction and additional income from the connection of local power systems will allow PJSC "Rosseti" to solve problems of digital transformation in the network without increasing the rate of tariff growth and the network component in the final price of electricity for consumers.

\section{References}

1. T. Dyatel Kommersant newspaper 143, 1 (2019)

2. Government of the Russian Federation. (2019, Mar. 20), N. 287, On Amendments to Certain Acts of the Government of the Russian Federation on meeting the needs of the authorities in ensuring the unified energy system of Russia, as well as improving the price dependent mechanism for reducing energy consumption and providing energy supply services system reliability

3. EnergyNet national technology initiative roadmap [Online].

Available: http://www.nti2035.ru/markets/docs/DK_energynet. pdf (Accessed on: Jul. 20, 2019)

4. The system operator familiarized electricity consumers with the prospects of introducing demand management technologies in the retail market 
[Online]. Available: http://www.odusv.socdu.ru/index.php?id=dr_news_view\&tx_ttnews[tt_n

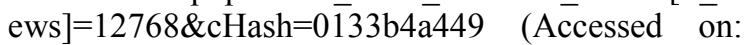
Jul.28, 2019)

5. N. Sidorova Energorynok 132, 28-32 (2015)

6. Peak Load Management Alliance "Demand Response Acronyms \& Glossary. Training Course Resource" [Online]. Available: https://www.peakload.org/assets/PLMADR\%20_Ac ronymsGlossary_053117.pdf (Accessed on: Jul. 10, 2019)

7. Global Demand Response Capacity is Expected to Grow to $144 \mathrm{GW}$ in 2025 [Online]. Available: https:/www.navigantresearch.com/news-andviews/global-demand-response-capacity-isexpected-to-grow-to-144-gw-in-2025 (Accessed on: Jul. 05, 2019)

8. F. Opadchiy, D. Holkin Demand management in the Russian Power Engineering: opportunities: expert and analytical report [Online]. Available: https://onedrive.live.com/?authkey=\%21 AL1vFI6tP 9alF9E\&cid=7589EC31D3F642F1\&id=7589EC31 D3F642F1\%218910\&parId=7589EC31D3F642F1\% 217875\&o=OneUp (Accessed on: Jul. 13, 2019)

9. Notification of competitive selection for electricity demand management services [Online]. Available: https://soups.ru/fileadmin/files/company/markets/dr/notice/no tice_dr_110619-1.pdf (Accessed on: Jun. 26, 2019)

10. Decisions of the commission on selection of power engineering entities providing demand management services [Online]. Available: https://soups.ru/?id=markets_asm_com_dr_dec (Accessed on: Jul. 06, 2019)

11. First selection of market participants in demand management in Russia: results and conclusions [Online]. Available: https://medium.com/internet-ofenergy/rus-demand-response-b2621247548a (Accessed on: Jul. 27, 2019)

12. F. Byk, L. Myshkina Rudenko International Conference "Methodological problems in reliability study of large energy systems", 69 book 2, 8188(Irkutsk, 2018)

13. Government of the Russian Federation (2009, Dec. 31), N 1220, About definition of the long-term rates of reliability indicators and quality of the delivered goods and the rendered services applied at establishment

14. P. Ilyushin Electro, Electrotechnics, power engineering, electrotechnical industry 4, 19-25 (2011)

15. E. N. Gezha, V. E. Glazyrin, G. V. Glazyrin, A. I. Marchenko, R. Iu. Semendiaev, A. G. Fishov [etc.] Releishchik 2, 24-31 (2018)

16. Conception Digital Transformation 2030 [Online]. Available: http://www.rosseti.ru/investment/Kontseptsiya_Tsifr ovaya_transformatsiya_2030.pdf (Accessed on: May 05, 2019) 